\title{
Effect of pasireotide on glucose- and growth hormone-related biomarkers in patients with inadequately controlled acromegaly
}

\author{
Herbert A. Schmid ${ }^{1}$ - Thierry Brue ${ }^{2} \cdot$ Annamaria Colao $^{3}$ - Mônica R. Gadelha ${ }^{4}$. \\ Ilan Shimon ${ }^{5} \cdot$ Karen Kapur $^{1} \cdot$ Alberto M. Pedroncelli $^{1} \cdot$ Maria Fleseriu $^{6}$
}

Received: 27 August 2015/Accepted: 5 February 2016/Published online: 23 February 2016

(c) The Author(s) 2016. This article is published with open access at Springerlink.com

\begin{abstract}
The purpose of this study was to gain more insight into the mechanism of action of pasireotide in patients who completed the PAOLA study. PAOLA was a 24-week, Phase III, randomized, three-arm study of pasireotide LAR 40 and $60 \mathrm{mg}$ versus octreotide LAR $30 \mathrm{mg}$ or lanreotide Autogel $120 \mathrm{mg}$ in patients with inadequately controlled acromegaly. The current work was a planned exploratory objective of the PAOLA study that evaluated changes in levels of growth hormone $(\mathrm{GH})$, insulin-like growth factor 1 (IGF-1), IGF-binding proteins (IGFBP-2, IGFBP-3), glycated haemoglobin $\left(\mathrm{HbA}_{1 \mathrm{c}}\right)$ and fasting plasma glucose (FPG) in each treatment arm. Responders to pasireotide LAR (mean GH levels $<2.5 \mu \mathrm{g} / \mathrm{L}$ and normal IGF-1 levels at 24 weeks) had lower GH and IGF-1 levels at baseline (GH $5.1 \mathrm{ng} / \mathrm{mL}$, IGF-1 $519 \mathrm{ng} / \mathrm{mL}$ ) than nonresponders (GH 7.9 ng/mL, IGF-1 672 ng/mL). Frequency
\end{abstract}

Electronic supplementary material The online version of this article (doi:10.1007/s12020-016-0895-8) contains supplementary material, which is available to authorized users.

Herbert A. Schmid

herbert.schmid@novartis.com

1 Novartis Pharma AG, Postfach, Basel, Switzerland

2 Centre National de la Recherche Scientifique, and Assistance Publique-Hôpitaux de Marseille, Hôpital de la Conception, Aix-Marseille University, Marseille, France

3 Università Federico II di Napoli, Naples, Italy

4 Hospital Universitário Clementino Fraga Filho, Universidade Federal do Rio de Janeiro, Rio de Janeiro, Brazil

5 Institute of Endocrinology and Metabolism, Rabin Medical Center, and Sackler School of Medicine, Tel-Aviv University, Petah Tikva, Israel

6 Northwest Pituitary Center, Oregon Health \& Science University, Portland, OR, USA of hyperglycaemia after pasireotide treatment was similar in responders and non-responders and depended more on the baseline FPG level. $47 \%$ of all patients treated with pasireotide LAR (40 or $60 \mathrm{mg}$ ) did not receive antidiabetic medication at any time during this study. This is the first study to evaluate the treatment effect of pasireotide on key hormonal and glycaemic biomarkers and to identify potential predictors of pasireotide-associated hyperglycaemia. Pre-treatment glucose status may be predictive of the development of pasireotide-associated hyperglycaemia. A large subset of patients with acromegaly does not experience major disturbances in glucose homeostasis while receiving pasireotide LAR.

Keywords PAOLA $\cdot$ Pasireotide $\cdot \mathrm{HbA}_{1 \mathrm{c}} \cdot$ Glucose . Hyperglycaemia $\cdot$ Acromegaly

\section{Introduction}

Medical therapy targeting somatostatin receptors is a mainstay treatment of disorders associated with hormone hypersecretion, such as acromegaly [1].

Five somatostatin receptor subtypes (SSTR1-5) have been identified [2]. In acromegaly, both first-generation somatostatin analogues, octreotide and lanreotide, exert their pharmacological effects mainly by binding to SSTR2 and to a lesser extent to SSTR5 [3], which are both expressed by most growth hormone (GH)-secreting pituitary adenomas [4]. The excess GH and insulin-like growth factor 1 (IGF-1) levels associated with acromegaly are suppressed in most patients following treatment with somatostatin analogues [5]. However, despite the clinical success of octreotide and lanreotide therapy in the treatment of acromegaly, approximately half of patients remain 
inadequately controlled [5] and are exposed to the deleterious effects of hormone hypersecretion, including significant co-morbidities, notably diabetes mellitus, increased mortality risk, and diminished quality of life [1]. Thus, alternative therapeutic options are needed.

Pasireotide, a multireceptor-targeted somatostatin analogue, has a high binding affinity for SSTR1, 2, 3, and 5 (exhibiting a 39-fold higher binding affinity for SSTR5 compared with octreotide [6]), with more profound suppression of GH and IGF-1 than octreotide [7, 8]. In a randomized, Phase III study in medically naïve patients with acromegaly, pasireotide LAR demonstrated superior efficacy over octreotide LAR [9]. More recently, in the PAOLA study, pasireotide LAR provided superior efficacy versus continued treatment with octreotide LAR or lanreotide Autogel (control group) in patients with inadequately controlled acromegaly [10]. In both of these studies, the safety profile of pasireotide LAR was generally similar to that of first-generation somatostatin analogues, except for the frequency and degree of hyperglycaemia.

Here, we report the results of a planned exploratory objective of the PAOLA study. To gain more insight into the mechanism of action of pasireotide in patients with acromegaly inadequately controlled with first-generation somatostatin analogues, changes in the clinically established efficacy biomarkers GH and IGF-1, as well as other biomarkers (IGF-binding protein [IGFBP]-2/3, glucose and glycated haemoglobin $\left[\mathrm{HbA}_{1 \mathrm{c}}\right]$ ), were assessed after pasireotide LAR treatment. Additionally, baseline levels of these markers were evaluated as potential predictors of clinical outcome.

\section{Subjects and methods}

\section{Patient population}

Male and female patients aged $\geq 18$ years with inadequately controlled acromegaly, defined as mean $\mathrm{GH}>2.5 \mu \mathrm{g} / \mathrm{L}$ and IGF-1 $>1.3$ times the sex- and ageadjusted upper limit of normal (ULN), were enrolled in this study. All patients had received treatment with octreotide LAR $30 \mathrm{mg}$ or lanreotide Autogel $120 \mathrm{mg}$ for at least 6 months prior to screening. Patients could have received prior surgery [10].

\section{Study design}

PAOLA was a prospective, multicentre, randomized, parallel-group study. The study design has been described more fully elsewhere [10]. Briefly, after a 4-week screening period, patients were randomized to receive doubleblind pasireotide LAR $40 \mathrm{mg}$ every 28 days for 24 weeks, or double-blind pasireotide LAR $60 \mathrm{mg}$ every 28 days for 24 weeks, or to continue on the same treatment with openlabel octreotide LAR $30 \mathrm{mg}$ or lanreotide Autogel $120 \mathrm{mg}$ every 28 days for 24 weeks (active control group). Transient dose decreases were permitted for tolerability issues in all treatment arms.

\section{Study objectives}

In the PAOLA study, the primary objective was to compare the proportion of patients achieving biochemical control, defined as mean GH levels $<2.5 \mu \mathrm{g} / \mathrm{L}$ and normalization of sex- and age-adjusted IGF- 1 at 24 weeks, with pasireotide LAR $40 \mathrm{mg}$ and pasireotide LAR $60 \mathrm{mg}$ separately versus continuing the same treatment with octreotide LAR $30 \mathrm{mg}$ or lanreotide Autogel $120 \mathrm{mg}$. The main secondary endpoint was the proportion of patients achieving normalization of sex- and age-adjusted IGF-1 at 24 weeks. The outcomes are fully described elsewhere [10].

The objectives of the current work were to assess changes in hormonal biomarkers (GH, IGF-1, IGFBP-2, and IGFBP-3) and glucose homeostasis biomarkers (fasting plasma glucose [FPG] and $\mathrm{HbA}_{1 \mathrm{c}}$ ) over time by treatment, GH/IGF-1 response status, and the use of antidiabetic medication.

\section{Biochemical assessments}

Blood samples for assessment of total IGF-1 were taken at the same visits as for the assessment of mean GH level, which was at screening, baseline, week 12, and week 24 (study completion). In addition, the mean IGF-1 level was also assessed at week 4. All blood samples were taken before the administration of study drug. Samples were analysed as follows: GH was assessed as the mean of an average of five individual measurements taken pre-dose at $0,30,60,90$, and $120 \mathrm{~min}$ within a 2 -h time period after $1 \mathrm{~h}$ at rest at the hospital and was measured using the Siemens Immulite 2000 S/N 1832 assay by a central contract research organization (Quest Diagnostics Clinical Trials, Valencia, CA, USA). IGF-1 and IGFBP-3 were analysed from individual serum samples using the Siemens Immulite $2000 \mathrm{~S} / \mathrm{N} 1832$ IGF-1 assay and the DPC Immulite 2000 IGFBP-3 assay, respectively (Quest Diagnostics Clinical Trials, Valencia, CA, USA); IGFBP-2 was analysed in serum using the R\&D Systems IGFBP-2 enzyme-linked immunosorbent assay (ELISA) kit (Cat\#DY674; BioAgilytix Labs, Durham, NC, USA); and FPG and $\mathrm{HbA}_{1 \mathrm{c}}$ were centrally analysed (Quest Diagnostics Clinical Trials, Valencia, CA, USA) by spectrophotometry using an Olympus AU 640/2700/5400 analyser and by high-performance liquid chromatography (HPLC) using a TOSOH G7/G8 automated HPLC analyser, respectively. 


\section{Statistical analyses}

The PAOLA study was not powered to assess specific biomarker-related hypotheses, so the statistical analyses of biomarker data should be considered as hypothesis driven and exploratory in nature. Analyses were conducted on patients who had available samples and who completed this study. Time profiles of GH, IGF-1, IGFBP-2, IGFBP-3, FPG, and $\mathrm{HbA}_{1 \mathrm{c}}$ levels were analysed together and separately in relevant subgroups of patients as follows: patients who were responders ( $\mathrm{GH}<2.5 \mu \mathrm{g} / \mathrm{L}$ and normal IGF-1) or non-responders $(\mathrm{GH} \geq 2.5 \mu \mathrm{g} / \mathrm{L}$ and/or IGF-1 $>$ ULN) at week 24; patients who did not receive antidiabetic medication at any time during the study; patients who were receiving antidiabetic medication at baseline; patients who initiated antidiabetic medication during the study (i.e. postbaseline); and patients with baseline FPG $>100$ and $\leq 100 \mathrm{mg} / \mathrm{dL}$. Hyperglycaemia was defined as one postbaseline FPG measurement of $\geq 126 \mathrm{mg} / \mathrm{dL}$ or receiving antidiabetic medication at any time during this study.

For biomarkers showing evidence of a skewed distribution, summaries of natural-log-transformed values, geometric means or medians were reported instead of arithmetic means. GH, IGF-1, IGFBP-2 and IGFBP-3 values reported below the lower limit of quantitation (LLOQ) or above the upper limit of quantitation (ULOQ) were imputed by LLOQ/2 or 0 and by ULOQ or the maximal value below the ULOQ, respectively. Statistical analyses were performed by Novartis using $\mathrm{R}$ version 3.0.1 or later and SAS version 9.2 or later.

\section{Results}

\section{Patient population}

The patient population has been described in more detail previously [10]. Briefly, a total of 198 patients were randomized: 65 each to pasireotide LAR 40 and $60 \mathrm{mg}$, and 68 to continued treatment with octreotide LAR $30 \mathrm{mg}$ or lanreotide Autogel $120 \mathrm{mg}$ (active control). Patient demographics, characteristics and disease history were generally similar across the three treatment groups at baseline. In total, $59(90.8 \%), 57(87.7 \%)$, and 65 (95.6\%) patients in the pasireotide LAR $40 \mathrm{mg}$, pasireotide LAR $60 \mathrm{mg}$, and active control groups completed the 24-week study, respectively.

\section{Changes in GH, IGF-1, IGFBP-2, and IGFBP-3 levels}

A decrease from baseline in GH, IGF-1, and IGFBP-3 levels was seen with both pasireotide and active control, with the magnitude of decrease being higher in the pasireotide LAR 40 and $60 \mathrm{mg}$ groups. Mean baseline values for GH, IGF-1, and IGFBP-3 were similar between pasireotide LAR and active control; however, baseline values for these parameters were lower among responders compared with non-responders to pasireotide (Table 1; Fig. 1). The overall median decrease from baseline to week 24 in GH and IGF-1 levels was numerically greater in the pasireotide LAR $60 \mathrm{mg}$ group compared with the $40 \mathrm{mg}$ group, with this dose dependency being most apparent among non-responders. Notably, decreases in both GH and IGF-1 among non-responders were more marked in both pasireotide arms compared with active control. For IGFBP2 , the median (interquartile range [IQR]) percentage changes from baseline in IGFBP-2 levels for pasireotide LAR $40 \mathrm{mg}(27 \%$ [73\%]), $60 \mathrm{mg}$ (36\% [86\%]) and active control (25\% [85\%]) were similar at week 24 (Fig. 1). However, for pasireotide LAR 40 and $60 \mathrm{mg}$, respectively, the median (IQR) percentage changes in IGFBP-2 levels from baseline to week 24 were $66 \%$ $(41 \%)$ and $37 \%(72 \%)$ for treatment responders versus $26 \%(80 \%)$ and $33 \%(91 \%)$ for non-responders.

\section{Changes in glycaemic biomarkers}

In patients receiving pasireotide LAR 40 and $60 \mathrm{mg}$, respectively, 44 and $49 \%$ did not receive antidiabetic medication during this study, 31 and $26 \%$ were receiving antidiabetic medication at study entry, and 25 and $25 \%$ of patients initiated antidiabetic medication during this study. Patients who received antidiabetic medication during pasireotide LAR treatment had higher baseline mean FPG and $\mathrm{HbA}_{1 \mathrm{c}}$ levels (Fig. 2) and more variable FPG levels (Supplementary Fig. 1) than patients who received no antidiabetic medication.

\section{Effect of baseline glucose status on glucose and $\mathrm{HbA}_{1 \mathrm{c}}$ levels during treatment}

Analysis of all patients revealed that those with baseline FPG $>100 \mathrm{mg} / \mathrm{dL}$ experienced higher values of FPG and $\mathrm{HbA}_{1 \mathrm{c}}$ after treatment with pasireotide LAR than patients with baseline FPG levels $\leq 100 \mathrm{mg} / \mathrm{dL}$ (Fig. 3; Table 2).

Among patients not receiving antidiabetic medication at baseline and with baseline FPG $\leq 100 \mathrm{mg} / \mathrm{dL}, 30 \%(6 / 20)$ and $48 \%(10 / 21)$ developed hyperglycaemia (FPG > $126 \mathrm{mg} / \mathrm{dL}$ ) during treatment with pasireotide LAR $40 \mathrm{mg}$ and $60 \mathrm{mg}$, respectively. In contrast, $52 \%(11 / 21)$ and $71 \%$ $(15 / 21)$ of patients with baseline FPG $>100 \mathrm{mg} / \mathrm{dL}$ developed hyperglycaemia during treatment (Fig. 4).

In the pasireotide LAR $40 \mathrm{mg}$ treatment group, geometric mean baseline FPG was $104.1 \mathrm{mg} / \mathrm{dL}$ (95\% CI 
Table 1 Effects of pasireotide and active control on GH, IGF-1, and IGFBP-3 after 24 weeks of treatment in all patients

\begin{tabular}{|c|c|c|c|c|c|c|}
\hline & $N^{\mathrm{a}}$ & $\begin{array}{l}\text { Baseline geometric } \\
\text { mean for all patients } \\
(95 \% \mathrm{CI})\end{array}$ & $\begin{array}{l}\text { Baseline geometric } \\
\text { mean for responders } \\
(95 \% \mathrm{CI})\end{array}$ & $\begin{array}{l}\text { Baseline geometric } \\
\text { mean for non-responders } \\
(95 \% \mathrm{CI})\end{array}$ & $\begin{array}{l}\text { Week } 24 \text { geometric } \\
\text { mean for all patients } \\
(95 \% \mathrm{CI})\end{array}$ & $\begin{array}{l}\text { Median (IQR) } \\
\text { change from } \\
\text { baseline to } \\
\text { week } 24 \text { for all } \\
\text { patients }(\%)\end{array}$ \\
\hline \multicolumn{7}{|c|}{ Pasireotide $40 \mathrm{mg}$} \\
\hline GH (ng/mL) & 59 & $7.9(6.0-10.3)$ & $6.2(4.2-9.0)$ & $8.3(6.1-11.4)$ & $3.6(2.5-5.3)$ & $-51.4(39.8)$ \\
\hline $\begin{array}{l}\text { IGF-1 } \\
\text { (ng/mL) }\end{array}$ & 59 & $640.7(586.1-700.3)$ & $462.1(391.6-545.3)$ & $684.8(625.2-750.1)$ & $400.1(335.3-477.3)$ & $-38.6(54.9)$ \\
\hline $\begin{array}{l}\text { IGFBP-3 } \\
(\mu \mathrm{g} / \mathrm{mL})\end{array}$ & 59 & $6.4(6.1-6.6)$ & $5.9(5.4-6.6)$ & $6.5(6.2-6.7)$ & $5.6(5.2-5.9)$ & $-13.5(22.1)$ \\
\hline \multicolumn{7}{|c|}{ Pasireotide $60 \mathrm{mg}$} \\
\hline GH (ng/mL) & 57 & $6.7(5.2-8.7)$ & $4.5(3.3-6.1)$ & $7.6(5.5-10.4)$ & $2.4(1.7-3.5)$ & $-61.3(43.0)$ \\
\hline $\begin{array}{l}\text { IGF-1 } \\
\quad(\mathrm{ng} / \mathrm{mL})\end{array}$ & 57 & $635.7(582.5-693.8)$ & $567.9(484.1-666.3)$ & $657.3(593.7-727.6)$ & $319.1(266.1-382.6)$ & $-48.9(42.2)$ \\
\hline $\begin{array}{l}\text { IGFBP-3 } \\
(\mu \mathrm{g} / \mathrm{mL})\end{array}$ & 57 & $6.1(5.9-6.4)$ & $6.0(5.5-6.6)$ & $6.2(5.9-6.5)$ & $5.2(4.8-5.6)$ & $-13.2(21.1)$ \\
\hline \multicolumn{7}{|c|}{ Pasireotide $40 / 60 \mathrm{mg}$} \\
\hline GH (ng/mL) & 116 & $7.3(6.0-8.8)$ & $5.1(4.0-6.6)$ & $7.9(6.4-9.9)$ & $3.0(2.3-3.9)$ & $-55.8(45.6)$ \\
\hline $\begin{array}{l}\text { IGF-1 } \\
\quad(\mathrm{ng} / \mathrm{mL})\end{array}$ & 116 & $638.2(599.8-679.2)$ & $519.2(460.1-586.0)$ & $671.6(627.7-718.7)$ & $358.0(315.1-406.8)$ & $-44.3(48.7)$ \\
\hline \multicolumn{7}{|l|}{ Active control } \\
\hline GH (ng/mL) & 65 & $6.9(5.7-8.2)$ & - & - & $5.3(4.1-6.8)$ & $-14.7(52.7)$ \\
\hline $\begin{array}{l}\text { IGF-1 } \\
\text { (ng/mL) }\end{array}$ & 65 & $648.5(594.3-707.7)$ & - & - & $561.1(508.2-619.5)$ & $-7.4(32.3)$ \\
\hline $\begin{array}{l}\text { IGFBP-3 } \\
(\mu \mathrm{g} / \mathrm{mL})\end{array}$ & 65 & $6.3(6.1-6.6)$ & - & - & $5.9(5.6-6.2)$ & $-5.2(18.1)$ \\
\hline
\end{tabular}

CI confidence interval, IQR interquartile range

a Number of patients with baseline measurements

91.9-117.8) and $105.6 \mathrm{mg} / \mathrm{dL}$ (95\% CI 101.0-110.5) for responders and non-responders, respectively, which increased to $124.4 \mathrm{mg} / \mathrm{dL}$ (95\% CI 115.0-134.6) and $123.8 \mathrm{mg} / \mathrm{dL}$ (95\% CI 113.4-135.2) at week 24 (median [IQR] percentage change from baseline, $19.4 \%$ [23.3\%] and $10.7 \%$ [16.5\%]). For the $60 \mathrm{mg}$ dose of pasireotide, responders and non-responders, respectively, had mean baseline FPG levels of $100.7 \mathrm{mg} / \mathrm{dL}$ (95 \% CI 88.3-114.7) and $106.0 \mathrm{mg} / \mathrm{dL}$ (95\% CI 101.1-111.1), which increased to $121.2 \mathrm{mg} / \mathrm{dL}$ (95\% CI $100.9-145.6$ ) and $141.0 \mathrm{mg} / \mathrm{dL}$ (95\% CI 127.5-155.8) at week 24 (median [IQR] percentage change from baseline, $19.4 \%$ [36.5\%] and $24.5 \%[27.0 \%])$.

The effect of pasireotide LAR treatment on $\mathrm{HbA}_{1 \mathrm{c}}$ was similar for responders and non-responders: the median (IQR) percentage changes from baseline to week 24 for responders were $9.2 \%(19.1 \%)$ and $10.6 \%(7.7 \%)$ for pasireotide LAR $40 \mathrm{mg}$ and $60 \mathrm{mg}$, respectively, and $6.7 \%(12.1 \%)$ and $12.1 \%$ (20.5\%) for non-responders. In addition to these findings, responder rates were found to be very similar in patients who did $(21 \%[n=13])$ and did not $(19 \%[n=10])$ receive antidiabetic medication.

\section{Discussion}

GH and IGF-1 are both closely linked to glycaemic status. GH suppresses insulin-mediated glucose uptake and enhances hepatic gluconeogenesis, while IGF-1, in addition to enhancing insulin action, also suppresses GH secretion [11]. These antagonistic effects act to modulate responsiveness to insulin. Sustained or excess GH secretion is associated with insulin resistance in both physiological (in healthy individuals during exercise and sleep) and pathological (acromegaly) states [12, 13], while the association between IGF-1 and insulin resistance is complex and remains less well understood.

IGF-1 (and, indirectly, GH) is regulated by a family of six homologous IGFBPs. Levels of IGFBP-3, the major binding protein for IGF-1, increase in response to increased levels of GH and IGF-1 [14, 15]. IGFBP-3 was once considered to be a potential biochemical marker of excess GH in patients with suspected acromegaly [16]. A relationship between increased levels of IGFBP-3 and hyperglycaemia has been suggested. In murine models, IGFBP-3 inhibits insulin-stimulated glucose uptake [17], 

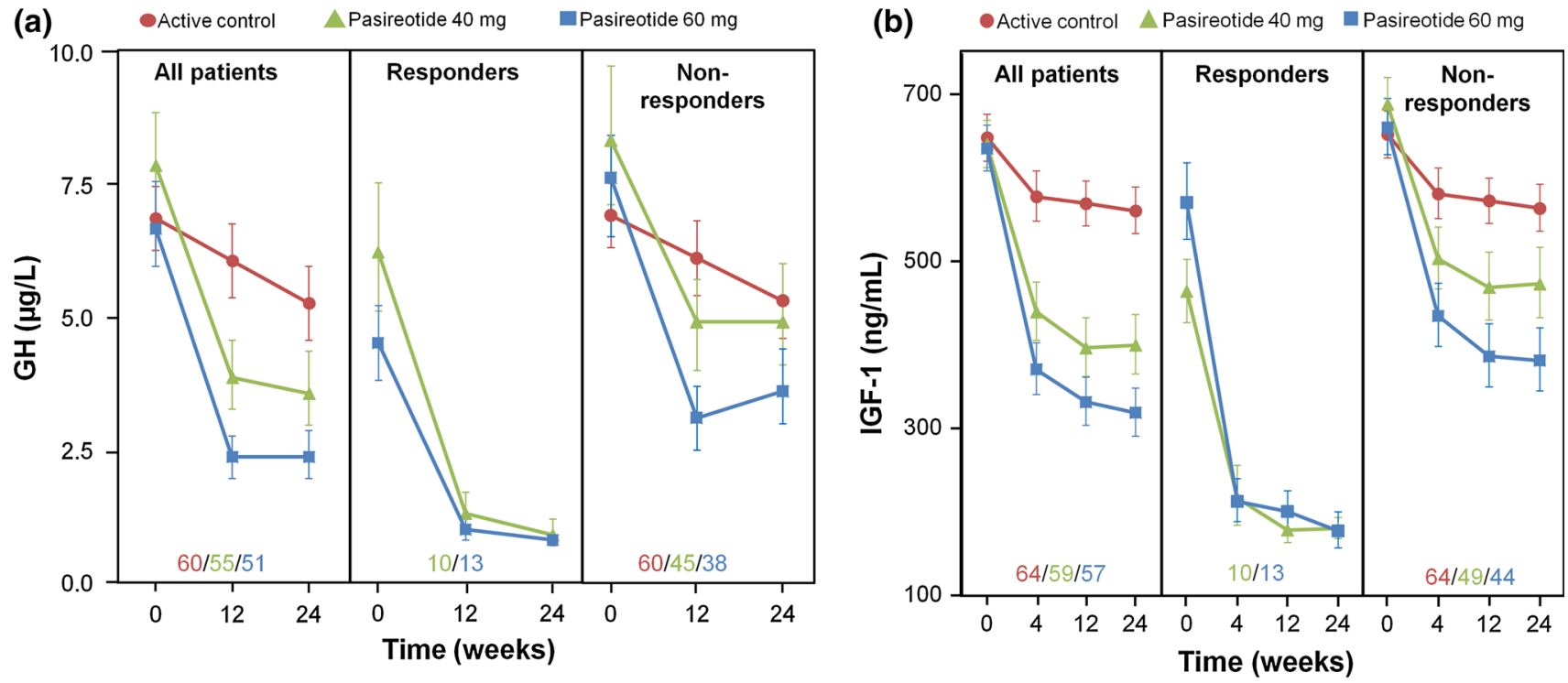

(c)

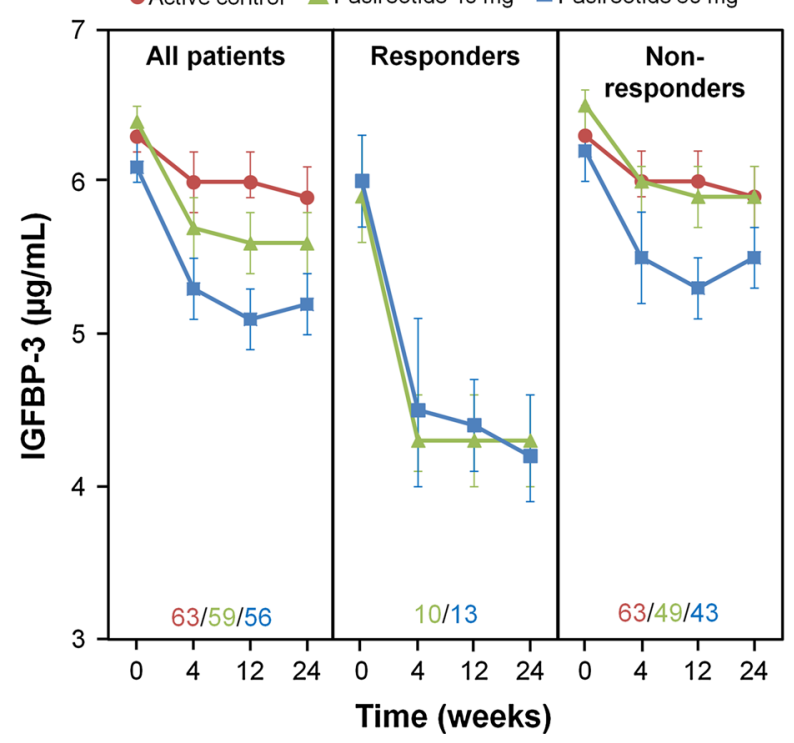

(d)

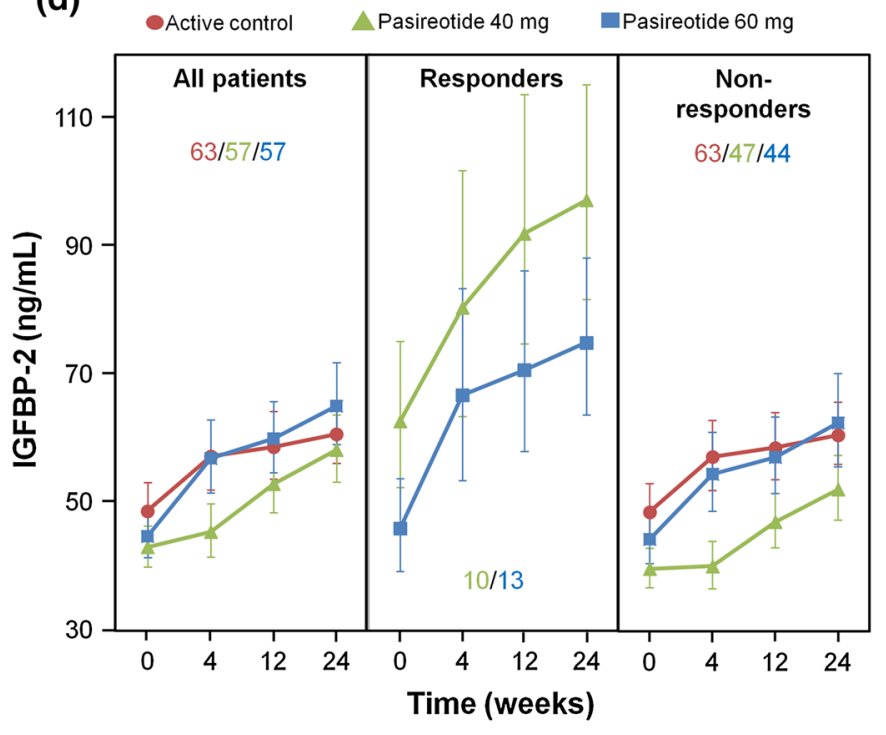

Fig. 1 Effect of pasireotide LAR and active control on a GH, b IGF-1, c IGFBP-3, and d IGFBP-2 levels during 24 weeks of treatment in all patients, responders, and non-responders. Data presented as geometric mean and $68 \%$ CI. Inset values represent patient numbers at 24 weeks

while over-expression of IGFBP-3 in male transgenic mice results in fasting hyperglycaemia, impaired glucose tolerance, and insulin resistance [18]. In the current analysis, dose-dependent reductions in GH, IGF-1, and IGFBP-3 levels were observed with pasireotide LAR, with levels of all three markers remaining consistently suppressed during the treatment period. When these findings were stratified according to whether patients were responders or non-responders to pasireotide LAR treatment, the responder group had lower GH levels and lower IGF-1 levels at baseline than the non-responder group. This finding is consistent with a previous population pharmacodynamic analysis of octreotide in patients with acromegaly, in which high baseline GH levels were associated with poorer responses to octreotide treatment [19]. For IGFBP-3, baseline levels were similar in both responders and non-responders.

Glucose homeostasis was relatively undisturbed throughout the treatment period in those patients receiving continued therapy with either octreotide or lanreotide. By contrast, there was a rapid initial increase in mean glucose and $\mathrm{HbA}_{1 \mathrm{c}}$ levels following treatment with pasireotide LAR, which subsequently plateaued, remaining stable to 24 weeks. This finding is consistent with previous Phase III study observations in which pasireotide-associated elevations in glucose levels typically plateaued after 
(a) Active control $\triangle$ Pasireotide $40 \mathrm{mg} \quad$ Pasireotide $60 \mathrm{mg}$

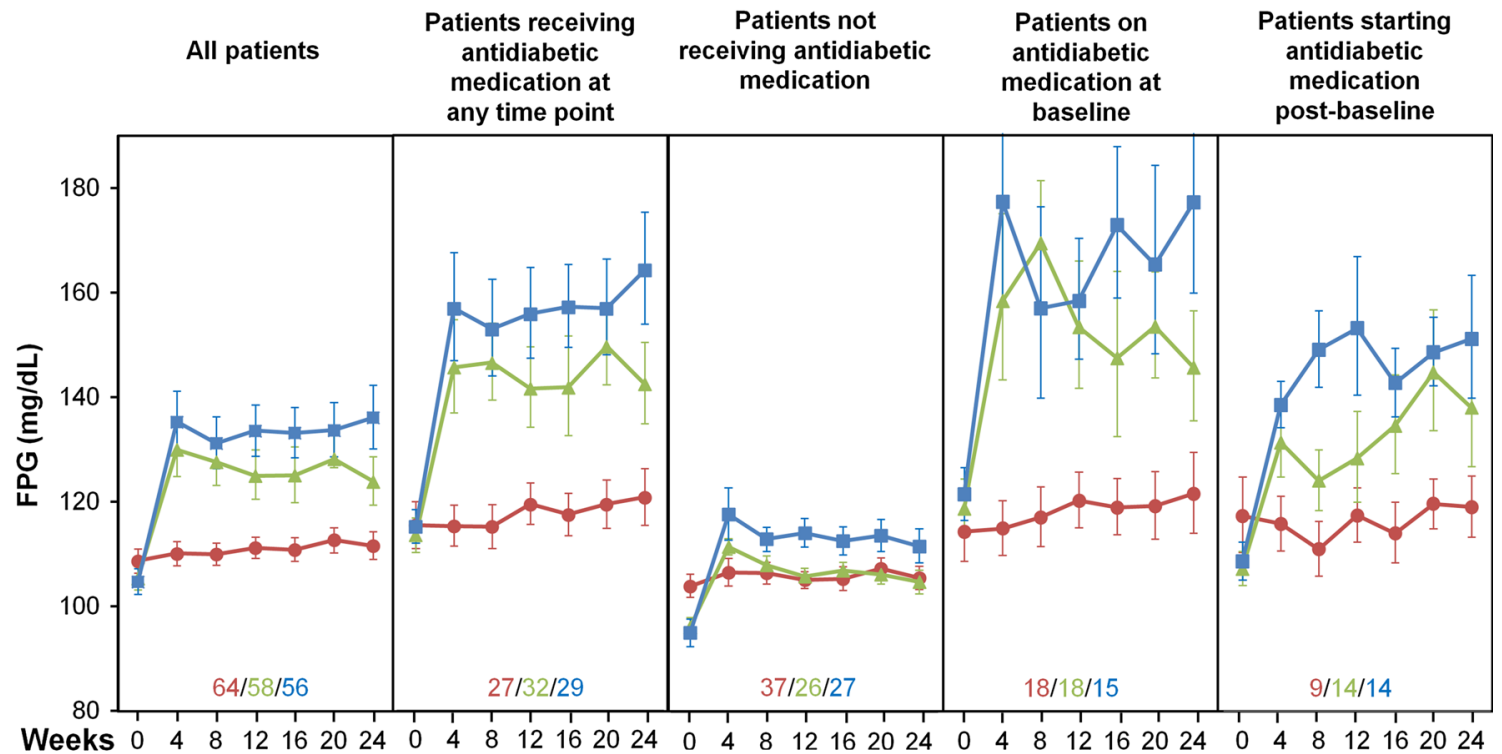

(b)

Active control $\triangle$ Pasireotide $40 \mathrm{mg} \quad$ Pasireotide $60 \mathrm{mg}$

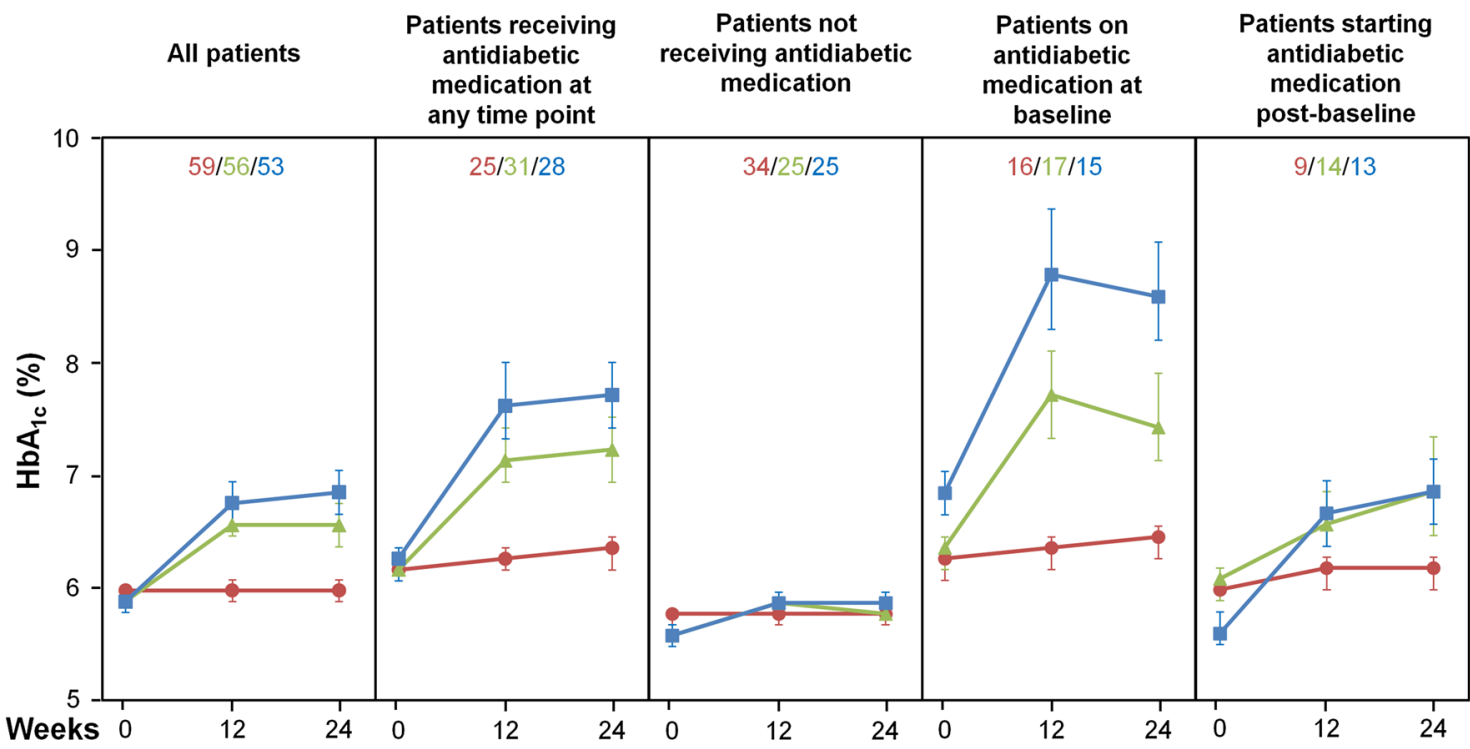

Fig. 2 Effect of pasireotide LAR and active control on a FPG and b $\mathrm{HbA}_{1 \mathrm{c}}$ levels in all patients, patients receiving antidiabetic medication at any time point, patients not receiving antidiabetic medication, patients receiving antidiabetic medication at baseline, and

approximately 2-3 months of pasireotide treatment in patients with acromegaly [20] and Cushing's disease [2123]. Patients with baseline glucose levels $>100 \mathrm{mg} / \mathrm{dL}$ experienced higher levels of glucose and $\mathrm{HbA}_{1 \mathrm{c}}$ after treatment with pasireotide LAR compared with patients with normoglycaemia at baseline. Although results vary, the data suggest that baseline glucose status is a potential predictive factor for the development of hyperglycaemia during pasireotide LAR treatment. patients starting antidiabetic medication post-baseline. Data presented as geometric mean and $68 \%$ CI. Inset values represent patient numbers at 24 weeks

Patients who received antidiabetic medication during pasireotide LAR treatment had higher baseline mean glucose and $\mathrm{HbA}_{1 \mathrm{c}}$ levels than patients who received no antidiabetic medication. Notably, approximately half of patients treated with pasireotide LAR did not receive antidiabetic medication at any time during this study. This finding suggests that a substantial proportion of patients with acromegaly do not experience disturbances in glucose 

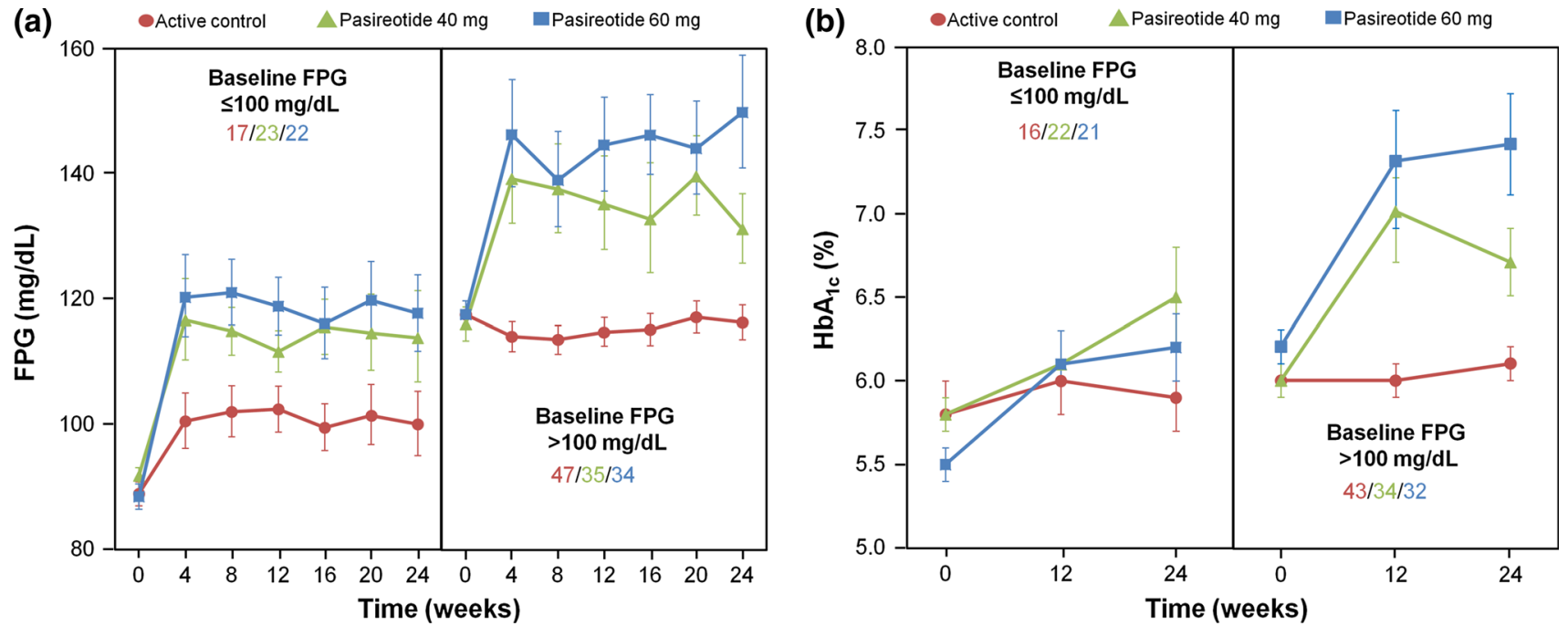

Fig. 3 Effect of pasireotide LAR and active control on a FPG and $\mathbf{b} \mathrm{HbA}_{1 \mathrm{c}}$ in patients with baseline FPG $\leq 100$ or $>100 \mathrm{mg} / \mathrm{dL}$. Data presented as geometric mean and $68 \%$ CI. Inset values represent patient numbers at 24 weeks

Table 2 Effect of pasireotide and active control on glucose and $\mathrm{HbA}_{1 \mathrm{c}}$ levels after 24 weeks of treatment, stratified according to baseline glucose status

\begin{tabular}{|c|c|c|c|c|c|c|c|}
\hline$N^{\mathrm{a}}$ & $\begin{array}{l}\text { Mean baseline } \\
\text { FPG }(\mathrm{mg} / \mathrm{dL}) \\
(95 \% \mathrm{CI})\end{array}$ & $\begin{array}{l}\text { Week } 24 \text { mean } \\
\text { FPG }(\mathrm{mg} / \mathrm{dL}) \\
(95 \% \mathrm{CI})\end{array}$ & $\begin{array}{l}\text { Median (IQR) } \\
\text { change from baseline } \\
\text { to week } 24(\%)\end{array}$ & $n^{\mathrm{b}}$ & $\begin{array}{l}\text { Mean } \\
\text { baseline } \\
\operatorname{HbA}_{1 \mathrm{c}}(\%)\end{array}$ & $\begin{array}{l}\text { Week } 24 \text { mean } \\
\mathrm{HbA}_{1 \mathrm{c}}(\%) \\
(95 \% \mathrm{CI})\end{array}$ & $\begin{array}{l}\text { Median (IQR) } \\
\text { change from } \\
\text { baseline to } \\
\text { week } 24(\%)\end{array}$ \\
\hline
\end{tabular}

\begin{tabular}{|c|c|c|c|c|c|c|c|c|}
\hline \multicolumn{9}{|l|}{ Pasireotide $40 \mathrm{mg}$} \\
\hline $\mathrm{FPG} \leq 100 \mathrm{mg} / \mathrm{dL}$ & 24 & $\begin{array}{l}91.8 \\
\quad(89.2-94.5)\end{array}$ & $\begin{array}{l}113.8 \\
\quad(100.1-129.4)\end{array}$ & $14.9(14.1)$ & 24 & $5.8(5.6-6.0)$ & $6.5(5.9-6.4)$ & $5.6(11.1)$ \\
\hline $\mathrm{FPG}>100 \mathrm{mg} / \mathrm{dL}$ & 35 & $\begin{array}{l}115.9 \\
(110.5-121.4)\end{array}$ & $\begin{array}{l}131.0 \\
\quad(120.3-142.7)\end{array}$ & $8.1(24.1)$ & 34 & $6.0(5.8-6.2)$ & $6.7(6.3-7.1)$ & $9.4(11.1)$ \\
\hline \multicolumn{9}{|l|}{ Pasireotide $60 \mathrm{mg}$} \\
\hline $\mathrm{FPG} \leq 100 \mathrm{mg} / \mathrm{dL}$ & 23 & $\begin{array}{l}88.4 \\
\quad(84.4-92.6)\end{array}$ & $\begin{array}{l}117.7 \\
\quad(106.1-130.5)\end{array}$ & $30.7(33.9)$ & 23 & $5.5(5.3-5.6)$ & $6.2(5.8-6.6)$ & $10.5(13.7)$ \\
\hline $\mathrm{FPG}>100 \mathrm{mg} / \mathrm{dL}$ & 34 & $\begin{array}{l}117.4 \\
\quad(113.3-121.8)\end{array}$ & $\begin{array}{l}149.6 \\
\quad(132.6-168.7)\end{array}$ & $22.4(26.7)$ & 33 & $6.2(5.9-6.5)$ & $7.4(6.8-8.0)$ & $12.1(21.0)$ \\
\hline \multicolumn{9}{|l|}{ Active control } \\
\hline $\mathrm{FPG} \leq 100 \mathrm{mg} / \mathrm{dL}$ & 18 & $\begin{array}{l}88.9 \\
\quad(85.2-92.8)\end{array}$ & $\begin{array}{l}100.0 \\
\quad(90.3-110.8)\end{array}$ & $7.0(9.6)$ & 17 & $5.8(5.6-6.1)$ & $5.9(5.6-6.2)$ & $-1.7(8.8)$ \\
\hline $\mathrm{FPG}>100 \mathrm{mg} / \mathrm{dL}$ & 47 & $\begin{array}{l}117.4 \\
\quad(113.1-121.8)\end{array}$ & $\begin{array}{l}116.2 \\
\quad(110.7-121.9)\end{array}$ & $-2.26(12.3)$ & 44 & $6.0(5.9-6.2)$ & $6.1(5.9-6.2)$ & $0(5.2)$ \\
\hline
\end{tabular}

${ }^{\text {a }}$ Number of patients with baseline measurements for FPG

b Number of patients with baseline measurements for $\mathrm{HbA}_{1 \mathrm{c}}$

homeostasis during pasireotide LAR treatment that warrants the initiation of antidiabetic medication.

Given the physiological role of natural somatostatin, as well as the SSTR binding profile of pasireotide [24], disturbances in glucose metabolism are not unexpected during treatment with pasireotide. Endocrine cells of the pancreas consist of $\alpha-, \beta-$, and $\delta$-cells, which secrete glucagon, insulin, and somatostatin, respectively, in response to changes in blood glucose. Insulin and glucagon are antagonistic hormones that regulate glucose uptake and metabolism, while localized release of somatostatin suppresses secretion of insulin and glucagon. In humans, glucagon-producing $\alpha$-cells predominantly express SSTR 2 [25], whereas SSTR5 and SSTR2 are found mainly on insulin-producing $\beta$-cells [26]. As pasireotide binds with higher affinity to SSTR5 than to SSTR2 [24], insulin secretion is substantially reduced while glucagon secretion is less markedly suppressed, resulting in an overall increase 

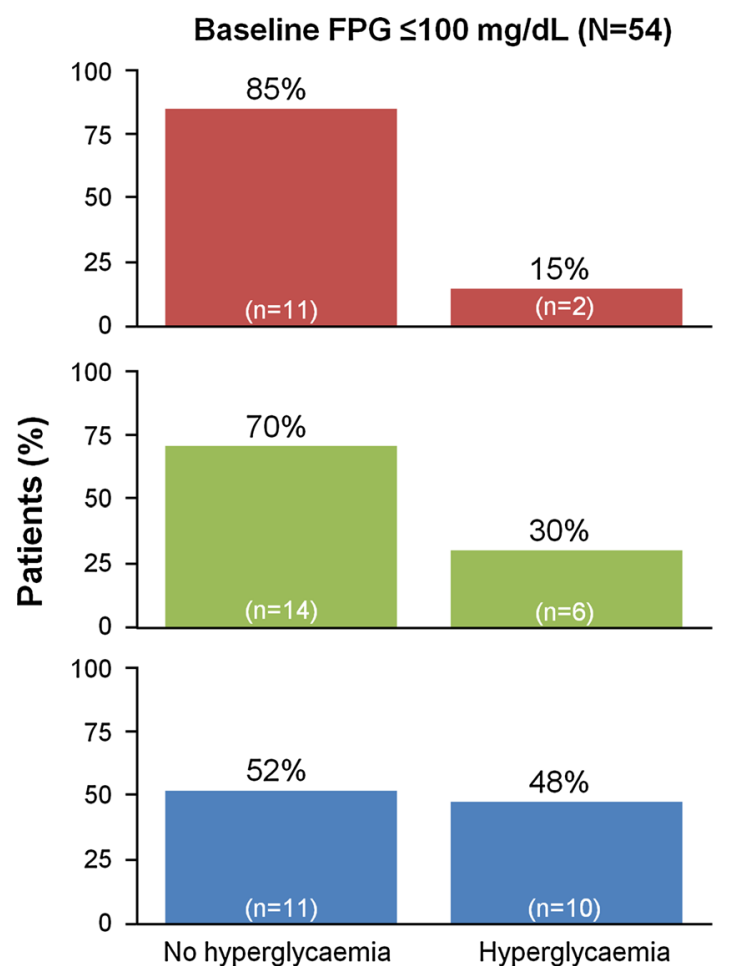

Fig. 4 Percentage of patients developing hyperglycaemia (postbaseline $\mathrm{FPG} \geq 126 \mathrm{mg} / \mathrm{dL}$ or receiving antidiabetic medication post-baseline) during treatment with pasireotide LAR or active

in glucose levels. Preclinical observations showed that pasireotide and octreotide suppressed insulin secretion to a similar degree, whereas pasireotide was a weaker inhibitor of glucagon secretion than octreotide [27]. Indeed, the SSTR5:SSTR2 activation ratio has been hypothesized to be the main driver of pasireotide-induced hyperglycaemia [27]. Schmid and Brueggen showed that co-administration of octreotide with pasireotide in rats negated the hyperglycaemia seen with pasireotide alone, implying that strong activation of SSTR2 by octreotide was sufficient to restore normoglycaemia [27].

The mechanism of pasireotide-induced hyperglycaemia has been explored in two studies conducted in healthy human volunteers. Henry et al. reported that twice-daily subcutaneous administration of 600 or $900 \mu \mathrm{g}$ pasireotide significantly decreased plasma levels of insulin, glucagonlike peptide 1 (GLP-1), and glucose-dependent insulinotropic polypeptide [28]. Glucagon secretion was only minimally affected, and insulin sensitivity was unaffected. The effects of pasireotide on insulin (via SSTR5) and glucagon secretion (via SSTR2) in this study were consistent with the SSTR binding profile of pasireotide. In the second study, the incretin-based antihyperglycaemic agents liraglutide (a GLP-1 agonist) and vildagliptin (a dipeptidyl peptidase 4 [DPP-4] inhibitor) were shown to effectively ameliorate hyperglycaemia when co-administered with pasireotide [29].
Baseline FPG $>100 \mathrm{mg} / \mathrm{dL}(\mathrm{N}=75)$
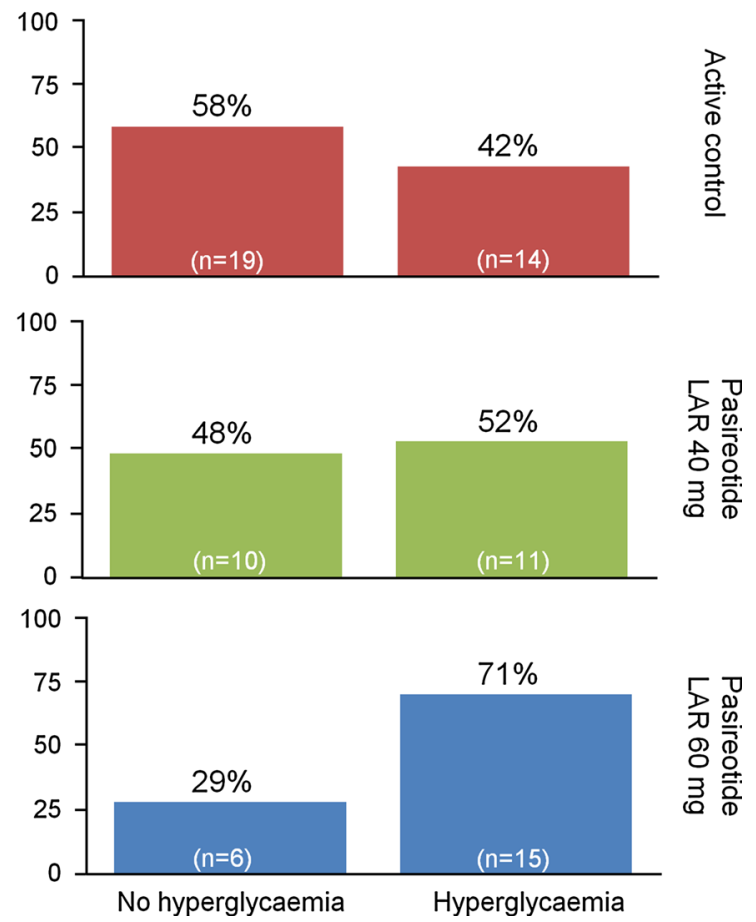

control, stratified by baseline FPG levels $\leq 100$ or $>100 \mathrm{mg} / \mathrm{dL}$, in patients without baseline antidiabetic medication

A similar finding has recently been reported for metformin-based antidiabetic therapy. In a sub-analysis of a 12-month, Phase III, randomized study in medically naïve patients with acromegaly [30], only those pasireotide patients who initiated antidiabetic medication at some point during the study, and not at baseline, were analysed $(n=57)$. In line with its role as first-line medical therapy for glycaemic management, metformin was the most commonly initiated antidiabetic medication. Metformin monotherapy $(n=24)$ or in combination with another oral antidiabetic medication $(n=19)$ was found to be effective in controlling $\left(\mathrm{HbA}_{1 \mathrm{c}}<7 \%\right)$ pasireotide-associated hyperglycaemia. Although metformin exerts its therapeutic effect mainly by reducing hepatic glucose production, it also reduces DPP-4 activity and increases GLP-1 secretion, which may be significant in the current context [31]. Taken together with the aforementioned studies, the role of the incretin system affecting insulin secretion is strongly implicated in the mechanism of action of pasireotide.

Endogenous processes may also potentially reduce the impact of pasireotide-induced hyperglycaemia. IGFBP-2 is a regulator of IGF-1, blocking the ability of the latter to bind to its receptor [32, 33], and it is also capable of modulating cellular processes independently of IGF-1 binding [34]. Although the physiological role of IGFBP-2 is not well defined, over-expression of IGFBP-2 in a transgenic mouse model was associated with improved 
insulin sensitivity compared with wild type [35]. Although data from the current analysis showed that responders to pasireotide LAR had increased levels of IGFBP-2 during treatment compared with non-responders, the effect of pasireotide LAR on levels of glycaemic biomarkers was found to be similar in both responders and non-responders. Whether or not elevated levels of IGFBP-2 confer increased insulin sensitivity, which may offset the effects of pasireotide LAR on glucose homeostasis in this setting, remains unknown. It is possible that the relatively shortterm duration of the primary study (6 months) was an insufficient timeframe to observe such a phenomenon.

\section{Conclusion}

Pasireotide LAR has demonstrated superior efficacy over octreotide LAR in medically naïve patients with acromegaly and, in the PAOLA study, in patients with uncontrolled acromegaly versus continued treatment with octreotide LAR or lanreotide Autogel. In both studies, a majority of patients experienced elevations in blood glucose levels with pasireotide treatment. Owing to the mechanism of action of pasireotide, elevated blood glucose despite improved efficacy is not unexpected.

Nevertheless, approximately half of patients with inadequately controlled acromegaly who completed the 24-week PAOLA study did not experience disturbances in glucose homeostasis during pasireotide LAR treatment that warranted the initiation of antidiabetic medication.

Responders to pasireotide LAR (mean GH levels $<2.5 \mu \mathrm{g} / \mathrm{L}$ and normalized IGF-1 levels) had lower GH and IGF-1 levels at baseline than non-responders. The effect of pasireotide LAR on blood glucose levels was similar in both responders and non-responders at week 24 and depended on the baseline glucose level.

Hyperglycaemia after pasireotide LAR treatment was observed in some patients who were normoglycaemic at baseline, but the effect was more pronounced in patients with pre-existing hyperglycaemia. Pre-treatment glucose status may thus be predictive of the development of pasireotide-associated hyperglycaemia and could play a future role in selecting appropriate or individualized therapy in patients with acromegaly.

Acknowledgments We thank Richard Ogilvy-Stewart PhD for medical editorial assistance with this manuscript. This study was funded by Novartis Pharma AG. The financial support for medical editorial assistance was provided by Novartis Pharmaceuticals Corporation.

\section{Compliance with ethical standards}

Conflict of interest HAS, AMP, and KK are employees of Novartis. MF has received institutional research support from
Novartis, Ipsen, and Pfizer, and consultancy fees from Novartis. MRG has received unrestricted research grants from Novartis and Pfizer, served as a principal investigator for Novartis and Ipsen clinical trials, served on advisory boards for Novartis, and received lecture fees from Novartis, Ipsen, and Pfizer. IS has received research grants, and consulting and lectureship fees from Novartis and Pfizer. AC has received speaker and consultancy fees from Novartis. TB has received institutional research support from Sandoz, Novo-Nordisk, and Pfizer, and consultancy and lectureship fees from Novartis, Ipsen, Shire, and Pfizer.

Ethical approval The primary study was conducted in accordance with the Declaration of Helsinki, and an independent ethics committee or institutional review board for each study site approved the study protocol.

Informed consent All patients provided written informed consent to participate.

Open Access This article is distributed under the terms of the Creative Commons Attribution 4.0 International License (http://crea tivecommons.org/licenses/by/4.0/), which permits unrestricted use, distribution, and reproduction in any medium, provided you give appropriate credit to the original author(s) and the source, provide a link to the Creative Commons license, and indicate if changes were made.

\section{References}

1. L. Katznelson, E.R. Laws Jr., S. Melmed et al., Acromegaly: an endocrine society clinical practice guideline. J. Clin. Endocrinol. Metab. 99, 3933-3951 (2014)

2. Y.C. Patel, Somatostatin and its receptor family. Front. Neuroendocrinol. 20, 157-198 (1999)

3. L.J. Hofland, S.W. Lamberts, The pathophysiological consequences of somatostatin receptor internalization and resistance. Endocr. Rev. 24, 28-47 (2003)

4. S. Melmed, Medical progress: acromegaly. N. Engl. J. Med. 355, 2558-2573 (2006)

5. J.D. Carmichael, V.S. Bonert, M. Nuño, D. Ly, S. Melmed, Acromegaly clinical trial methodology impact on reported biochemical efficacy rates of somatostatin receptor ligand treatments-a meta-analysis. J. Clin. Endocrinol. Metab. 99, 1825-1833 (2014)

6. H.A. Schmid, P. Schoeffter, Functional activity of the multiligand analog SOM230 at human recombinant somatostatin receptor subtypes supports its usefulness in neuroendocrine tumors. Neuroendocrinology 80(Suppl 1), 47-50 (2004)

7. H.A. Schmid, A.P. Silva, Short- and long-term effects of octreotide and SOM230 on GH, IGF-I, ACTH, corticosterone and ghrelin in rats. J. Endocrinol. Invest. 28(11 Suppl), 28-35 (2005)

8. G. Weckbecker, U. Briner, I. Lewis, C. Bruns, SOM230: a new somatostatin peptidomimetic with potent inhibitory effects on the growth hormone/insulin-like growth factor-I axis in rats, primates, and dogs. Endocrinology 143, 4123-4130 (2002)

9. A. Colao, M.D. Bronstein, P. Freda et al., Pasireotide versus octreotide in acromegaly: a head-to-head superiority study. J. Clin. Endocrinol. Metab. 99, 791-799 (2014)

10. M.R. Gadelha, M.D. Bronstein, T. Brue et al., Pasireotide versus continued treatment with octreotide or lanreotide in patients with inadequately controlled acromegaly (PAOLA): a randomised, phase 3 trial. Lancet Diabetes Endocrinol. 2, 875-884 (2014)

11. D.R. Clemmons, The relative roles of growth hormone and IGF-1 in controlling insulin sensitivity. J. Clin. Invest. 113, 25-27 (2004) 
12. R.A. Rizza, L.J. Mandarino, J.E. Gerich, Effects of growth hormone on insulin action in man. Mechanisms of insulin resistance, impaired suppression of glucose production, and impaired stimulation of glucose utilization. Diabetes 31, 663-669 (1982)

13. I. Hansen, E. Tsalikian, B. Beaufrere et al., Insulin resistance in acromegaly: defects in both hepatic and extrahepatic insulin action. Am. J. Physiol. 250, E269-E273 (1986)

14. W.W. de Herder, A.J. van der Lely, J.A. Janssen et al., IGFBP-3 is a poor parameter for assessment of clinical activity in acromegaly. Clin. Endocrinol. (Oxf.) 43, 501-505 (1995)

15. S. Grinspoon, D. Clemmons, B. Swearingen, A. Klibanski, Serum insulin-like growth factor-binding protein-3 levels in the diagnosis of acromegaly. J. Clin. Endocrinol. Metab. 80, 927-932 (1995)

16. J.A. Wass, Growth hormone, insulin-like growth factor-I and its binding proteins in the follow-up of acromegaly. J. Endocrinol. 155(Suppl 1), S17-S19 (1997)

17. P.M. Yamada, H.H. Mehta, D. Hwang et al., Evidence of a role for insulin-like growth factor binding protein (IGFBP)-3 in metabolic regulation. Endocrinology 151, 5741-5750 (2010)

18. J.V. Silha, Y. Gui, L.J. Murphy, Impaired glucose homeostasis in insulin-like growth factor-binding protein-3-transgenic mice. Am. J. Physiol. Endocrinol. Metab. 283, E937-E945 (2002)

19. E. Comets, F. Mentre, P. Grass et al., Population pharmacodynamic analysis of octreotide in acromegalic patients. Clin. Pharmacol. Ther. 73, 95-106 (2003)

20. M. Sheppard, M.D. Bronstein, P. Freda et al., Pasireotide LAR maintains inhibition of GH and IGF-1 in patients with acromegaly for up to 25 months: results from the blinded extension phase of a randomized, double-blind, multicenter, phase III study. Pituitary 18, 385-394 (2015)

21. A. Colao, S. Petersenn, J. Newell-Price et al., A 12-month phase 3 study of pasireotide in Cushing's disease. N. Engl. J. Med. 366, 914-924 (2012)

22. J. Bertherat, J. Schopohl, W.H. Ludlam et al., Long-term pasireotide use leads to significant and sustained improvements in the signs and symptoms of Cushing disease: 24-month results from a randomized Phase III study. Endocr. Rev. 33, abst SUN-734 (2012)

23. J. Bertherat, W.H. Ludlam, R. Pivonello et al., Pasireotide as a long-term treatment for patients with Cushing disease: 24-month safety results from a randomized Phase III study. Endocr Rev 33, abst SUN-735 (2015)
24. C. Bruns, I. Lewis, U. Briner, G. Meno-Tetang, G. Weckbecker, SOM230: a novel somatostatin peptidomimetic with broad somatotropin release inhibiting factor (SRIF) receptor binding and a unique antisecretory profile. Eur. J. Endocrinol. 146, 707-716 (2002)

25. V. Singh, M.D. Brendel, S. Zacharias et al., Characterization of somatostatin receptor subtype-specific regulation of insulin and glucagon secretion: an in vitro study on isolated human pancreatic islets. J. Clin. Endocrinol. Metab. 92, 673-680 (2007)

26. Y. Zambre, Z. Ling, M.C. Chen et al., Inhibition of human pancreatic islet insulin release by receptor-selective somatostatin analogs directed to somatostatin receptor subtype 5. Biochem. Pharmacol. 57, 1159-1164 (1999)

27. H.A. Schmid, J. Brueggen, Effects of somatostatin analogues on glucose homeostasis in rats. J. Endocrinol. 212, 49-60 (2012)

28. R.R. Henry, T.P. Ciaraldi, D. Armstrong et al., Hyperglycemia associated with pasireotide: results from a mechanistic study in healthy volunteers. J. Clin. Endocrinol. Metab. 98, 3446-3453 (2013)

29. A. Breitschaft, K. Hu, R.K. Hermosillo, C. Darstein, G. Golor, Management of hyperglycemia associated with pasireotide (SOM230): healthy volunteer study. Diabetes Res. Clin. Pract. 103, 458-465 (2014)

30. A. Colao, F. Gu, M. Gadelha et al., Metformin-based oral antidiabetic therapy is effective at controlling hyperglycemia associated with pasireotide in patients with acromegaly, in 97th Annual Meeting of the Endocrine Society, San Diego, CA, USA, 2-8 March abst PP09-2 (2015)

31. A. Maida, B.J. Lamont, X. Cao, D.J. Drucker, Metformin regulates the incretin receptor axis via a pathway dependent on peroxisome proliferator-activated receptor-alpha in mice. Diabetologia 54, 339-349 (2011)

32. S.M. Firth, R.C. Baxter, Cellular actions of the insulin-like growth factor binding proteins. Endocr. Rev. 23, 824-854 (2002)

33. K.M. Kelley, Y. Oh, S.E. Gargosky et al., Insulin-like growth factor-binding proteins (IGFBPs) and their regulatory dynamics. Int. J. Biochem. Cell Biol. 28, 619-637 (1996)

34. A. Hoeflich, R. Reisinger, H. Lahm et al., Insulin-like growth factor-binding protein 2 in tumorigenesis: protector or promoter? Cancer Res. 61, 8601-8610 (2001)

35. S.B. Wheatcroft, M.T. Kearney, A.M. Shah et al., IGF-binding protein-2 protects against the development of obesity and insulin resistance. Diabetes 56, 285-294 (2007) 